\title{
Presence and significance of Helicobacter spp. in the gastric mucosa of Portuguese dogs
}

\author{
Irina Amorim ${ }^{1,2,3}$, Annemieke Smet ${ }^{4}$, Odete Alves ${ }^{3}$, Silvia Teixeira ${ }^{3}$, Ana Laura Saraiva ${ }^{3,5}$, Marian Taulescu ${ }^{6}$, \\ Celso Reis ${ }^{1,2,3,7}$, Freddy Haesebrouck ${ }^{4}$ and Fátima Gärtner ${ }^{1,2,3^{*}}$
}

\begin{abstract}
Background: Non-Helicobacter pylori Helicobacters (NHPH) are also able to cause disease in humans. Dogs are a natural reservoir for many of these species. Close and intense human contact with animals has been identified as a risk factor and therefore, an important zoonotic significance has been attributed to NHPH.

Methods: To determine the prevalence of Helicobacter species and the gastric histopathological changes associated, gastric mucosa samples of 69 dogs were evaluated.

Results: Only one dog presented a normal histopathological mucosa with absence of spiral-shaped organisms. A normal gastric mucosa and the presence of spiral-shaped bacteria was observed in two dogs. All remaining animals presented histopathological changes representative of gastritis. Helicobacter species were detected in 60 dogs (87.0\%) by at least one detection method. Histological, histochemical and immunohistochemical evaluations revealed that Helicobacter spp. were present in 45 (65.2\%), 52 (75.4\%) and 57 (82.6\%) dogs, respectively. Spiral-shaped bacteria were detected by qPCR analysis in 33 (47.8\%) dogs. H. heilmannii-like organisms were identified in 22 animals (66.7\%) and predominantly in the antral gastric region. H. salomonis was the second most prevalent species (51.5\%) although it was mainly found in association with other Helicobacter spp. and in the body gastric region. H. bizzozeronii and $\mathrm{H}$. felis were less frequently detected.

Conclusions: It was concluded that, despite the high incidence and worldwide distribution of gastric NHPH in dogs, the presence of specific Helicobacter species may vary between geographic regions. NHPH infections were significantly accompanied by mild to moderate intraepithelial lymphocyte infiltration and mild to moderate gastric epithelial injury, but a clear relationship between gastritis and Helicobacter infection could not be established.
\end{abstract}

Keywords: Canine gastric mucosa, Dogs, Non-Helicobacter pylori helicobacters (NHPH), Histochemistry, Immunohistochemistry (IHC), Polymerase chain reaction (PCR), Stomach

\section{Introduction}

The genus Helicobacter is composed of at least 40 species [1]. Among these, $H$. pylori is considered as an important pathogen whose natural host is man but its presence in the canine stomach has been rarely reported [2-4].

A large number of non-Helicobacter pylori Helicobacter species (NHPH) have also been recognized in humans and in several animals. Previously, NHPH were generally referred to as $H$. heilmannii sensu lato (s.l.) and included

\footnotetext{
*Correspondence: fgartner@ipatimup.pt

${ }^{1}$ Instituto de Investigação e Inovação em Saúde, Universidade do Porto, Porto, Portugal

${ }^{2}$ IPATIMUP - Institute of Molecular Pathology and Immunology of the University of Porto, Rua Dr. Roberto Frias s/n, 4200-465 Porto, Portugal Full list of author information is available at the end of the article
}

H. suis, a species colonizing the stomachs of pigs and a group of species known to colonize the gastric mucosa of dogs and cats: $H$. felis, $H$. bizzozeronii, $H$. salomonis, $H$. cynogastricus, $H$. baculiformis and $H$. heilmannii sensu stricto (s.s.) [5]. Most of these gastric NHPH are also able to cause disease in humans [6,7]. Close and intense human contact with animals has been identified as a risk factor and therefore, an important zoonotic significance has been attributed to NHPH $[6,8,9]$.

In pet animals, gastric Helicobacter spp. have been frequently described with a prevalence ranging from 67$86 \%$ in clinically healthy dogs and $61-100 \%$ in animals presenting chronic vomiting [10-14]. These microorganisms were detected in the stomach of about $100 \%$ of 
laboratory Beagle dogs and dogs from local shelters [15-17]. The predominant gastric Helicobacter spp. in cats and dogs are H. felis, H. bizzozeronii and H. heilmannii sensu stricto (s.s.), while H. salomonis is less often detected and the prevalence of $H$. cynogastricus and $H$. baculiformis has not yet been studied [9,18-20]. Mixed infections with different species can also occur $[3,19]$.

While many studies have reported that the fundus and body have higher bacterial density and a higher probability of finding Helicobacter spp. [17,21,22] others have found no significant differences between the density of $\mathrm{NHPH}$ in the fundus, body and antrum [2,23-26] of the canine stomach. The discrepancies in these results can be attributed to the different laboratory diagnostic methodologies used by the various research groups.

The diagnostic methods used for Helicobacter spp. can be non-invasive and invasive [24]. Non-invasive methods like serology or detection of bacterial DNA and antigens in stools do not require a gastric biopsy or anaesthesia. The invasive methods, like bacterial cultures, histopathology, smears, electron microscopy or polymerase chain reaction (PCR) may require a gastric biopsy, which is frequently obtained through endoscopy under anaesthesia or by necropsy. Typically Helicobacter organisms are not easily visualized with the haematoxylin and eosin (HE) stain and so, their direct observation in biopsied specimens is highlighted by the use of special stains, such as the modified Giemsa (MG) stain. More elaborate and sensitive Helicobacter-detection methods such as immunohistochemistry (IHC) or polymerase chain reaction (PCR) are research tools rarely used in a diagnostic setting.

Several investigations have discussed the prevalence of Helicobacter spp. in dogs $[2,10,11,14,16]$ but in only few studies the specific species present in the canine stomach were determined $[4,19,27,28]$. The accurate identification of the gastric helicobacters to the species level is essential in order to determine the prevalence and clinical significance of all taxa. The aim of this study was to determine the prevalence of different gastric Helicobacter species present in distinct stomach regions of the canine stomach (body and antrum) using histological, histochemical, immunohistochemical and molecular diagnostic techniques. The degree of colonization was characterized and correlated with the respective histopathological changes in the canine gastric mucosa.

\section{Methods}

\section{Sample collection}

Gastric tissues were obtained from 69 dogs (45 male and 24 female, ranging in age from 3 months to 15 years). The samples were randomly selected from the archives of the Laboratory of Veterinary Pathology, ICBAS-UP (Portugal) where they were received between 2010 and 2013. Samples were obtained from 20 dogs during endoscopic procedures, from five during surgery and from 44 dogs during necropsy examinations. All the procedures (surgical excision and necropsy examination) were performed in a clinical context attempting to treat the animals based on the best clinical judgment of their attending practitioners. The use of the excised tissues for research was explained to the owners and an informed consent was obtained for each case. None of the actions were taken solely for research purposes and the investigators had no influence on the selection and execution of such procedures. Only gastric samples in good condition of preservation were included in this study.

Tissues were fixed in $10 \%$ neutral buffered formalin and embedded in paraffin wax. Three consecutive sections of $3 \mu \mathrm{m}$ were made, one being stained with $\mathrm{HE}$, another with a MG stain and the third was used for immunohistochemical staining.

\section{Sample evaluation}

The gastric samples were evaluated independently by two observers (IA and FG). Histopathological parameters such as alterations in cellularity, fibrosis of the lamina propria and gland atrophy were analysed according to the World Small Animal Veterinary Association (WSAVA) guidelines [29]. The degree of morphological features and inflammatory changes was graded as normal, mild, moderate or marked by using the available WSAVA gastrointestinal standardization visual analogue [29].

The microscopic evaluation was performed by analysing the entire section of the gastric tissue. The presence of Helicobacter spp. was assessed by HE and MG stains and by IHC. A dog was classified as Helicobacter positive when one of these methods gave a positive result. Additionally, bacterial density colonization was quantified: +, few organisms ( $<10$ organisms/400x); ++ , moderate number of organisms (10 to 50 organisms/400x); +++, large number of organisms ( $>50$ organisms/400x) [24].

\section{Immunohistochemistry}

For the immunohistochemical study, sections were deparaffinised, hydrated and antigen retrieval was performed in a pressure cooker in $10 \mathrm{mmol} / \mathrm{L}$ sodium citrate buffer, $\mathrm{pH}$ 6.0, for 2 minutes (min). Slides were cooled for $10 \mathrm{~min}$ at room temperature and rinsed twice in triphosphate buffered saline (TBS) for 5 min. The NovolinkTM MaxPolymer detection system (Novocastra, Newcastle, UK) was used for visualisation, according to the manufacturer's instructions. After blocking endogenous peroxidase with $3 \%$ hydrogen peroxide in methanol for $10 \mathrm{~min}$, sections were incubated overnight at $4^{\circ} \mathrm{C}$, with a polyclonal antiserum against H. pylori (RBK012; Zytomed, German) which shows immunoreactivity with a wide range of bacteria belonging to the Helicobacter genus. Sections were rinsed with TBS between each step of the procedure. Colour was 
developed for up to $7 \mathrm{~min}$ at room temperature with 3,3'diamino-benzidine (DAB) (Sigma, St. Louis, MO) and sections were then lightly counterstained with haematoxylin, dehydrated and mounted. Positive immunoreactivity was recorded as a distinct golden-brown labelling of the bacteria located on mucosal surface, in gastric pits or glands and in parietal cells.

\section{Extraction, PCR amplification and sequencing of DNA}

DNA was extracted from 5 consecutive slices of $20 \mu \mathrm{M}$ using a DNeasy Blood and Tissue Kit (Qiagen), according to the manufacturer's instructions. Helicobacter speciesspecific qPCRs based on a short fragment of the urease A and $\mathrm{B}$ genes were developed for the identification of $H$. heilmannii s.s., H. felis, H. bizzozeronii and H. salomonis. For generation of standards for each qPCR, a large part of the ureAB gene cluster from $H$. heilmannii ASB1 (1224 bp), H. felis CS1 (1228 bp), H. salomonis R1053 (1224 bp) and H. bizzozeronii R1051 (1230 bp) was amplified using primers U430F and U1735R, as described previously [30]. The standard consisted of 10-fold-dilutions starting at $10^{8} \mathrm{PCR}$ amplicons for each $10 \mu \mathrm{l}$ of reaction mixture. One $\mu \mathrm{l}$ of extracted DNA template was suspended in a $10 \mu \mathrm{l}$ reaction mixture consisting of $0.25 \mu \mathrm{l}$ of forward and reverse primers (Table 1), $3.5 \mu \mathrm{l} \mathrm{HPLC}$ water and $5 \mu \mathrm{l} \mathrm{SensiMix}{ }^{\mathrm{Tm}}$ SYBR No-ROX (Bioline Reagents Ltd, UK). Both standards and samples were run in duplicate on a CFX96 $6^{\mathrm{m}}$ RT-PCR System with a C1000 Thermal Cycler (Bio-Rad, Hercules CA, USA). The Bio-Rad CFX Manager (version 1.6) software was used for calculation of threshold cycles $(\mathrm{Ct}$ )-values and melting curve analysis of amplified DNA. The average values of the duplicates were used for quantification of Helicobacter DNA in the tissue samples. To exclude false positive samples, the amplicons from each positive sample were sequenced.

\section{Statistical analysis}

Pearson's chi-square test and Fisher's exact test were used to determine the dependence between two categories. $\mathrm{p}$ values $<0.05$ were considered as statistically significant. Statistical analysis was performed using the statistical package SPSS 16.0 (SPSS Inc., Produtos e Serviços de Estatística Lda, Lisbon, Portugal).

\section{Results}

A total of 117 gastric samples (66 from the body region and 51 from the antrum region) were analysed.

Among the 69 animals, both gastric regions were available for evaluation in 48 dogs whereas only body or antrum regions were available in 18 and three dogs, respectively.

Of the 69 dogs, only one presented a normal histopathological mucosa with absence of spiral-shaped organisms. A normal gastric mucosa and the presence of spiral-shaped bacteria was observed in two dogs (2.9\%). The remaining animals, presented histopathological changes representative of gastritis (66/69 or $95.7 \%)$ (Table 2). On the basis of histopathological changes in the gastric mucosa, we diagnosed a mild to moderate chronic gastritis in $88.4 \%(61 / 69)$ affecting the gastric body of $51.5 \%(34 / 66)$ and the antral region of $92.2 \%$ (47/51) of the animals.

Both mild to moderate epithelial injuries and mild to moderate intraepithelial lymphocyte infiltration were found in $88.4 \%(61 / 69)$.

Gastric mucosal atrophy, glandular nesting or fibrosis was present in $44.9 \%$ dogs (31/69). In $18.2 \%$ of the animals this alteration was observed in the body region $(12 / 66)$ and in $47.1 \%$ in the antrum region $(24 / 51)$ of the canine stomach.

Abnormal neutrophilic infiltration was only detected in the stomach antrum of two animals: in one, this alteration was mild and in the other, it was marked and associated with gastric ulceration. Other inflammatory cells, consisting in mild infiltration of mast cells, were observed in the body region of four animals and in the antrum of two animals.

Among all animals, 87.0\% were positive (60/69) (Figure 1A) and $13.0 \%$ were negative for Helicobacter spp. (9/69), irrespective of the test used to detect the bacteria. Regardless of the stomach location, Helicobacter spp. were observed using HE, MG and IMC in 65.2\% (45/69), 75.4\% (52/69) and $82.6 \%(57 / 69)$ of the dogs, respectively. With HE staining, spiral-shaped bacteria were detected in $62.1 \%$ of

Table 1 List of primers used for qPCR

\begin{tabular}{lll}
\hline Primer name & Nucleotide sequence & Specificity \\
\hline Hfel_F2 & GCT GGT GGC ATC GAT ACG CAT & H. felis \\
Hfel_R2 & TTा TTA GAT TAG CGC GTC CGG GA & H. felis \\
HH_FQ & GGC TCT GCG TAG GAC CTG CTA CAG AAG CTC TC & H. heilmannii s.S. \\
HH_RQ & GGC TGT AGG GAT TTG TTG AGG AGA AAT G & H. heilmannii s.S. \\
Hsal_FQ & CTC TTA TGA GTT GGA CTT GGT GCT CAC CAA T & H. salomonis \\
Hsal_RQ & TTT GCC ATC TTT AAT TCC AAT GTC GGC & H. salomonis \\
Hbizz_FQ & AAT CTT TGC GTG GGC CCT GCT ACT GAG & H. bizzozeronnii \\
Hbizz_RQ & CTG GCA AAT GCT GTG GGG ATT TGT TGG & H. bizzozeronnii \\
\hline
\end{tabular}


Table 2 Table summarising the histopathological alterations and colonisation density observed in the canine stomach, according to the positive NHPH species-specific PCR results, positive genus results and negative results

\begin{tabular}{|c|c|c|c|c|c|c|c|c|c|c|c|c|}
\hline & \multicolumn{9}{|c|}{ PCR positive results with specific species identification, regardless gastric location (percent\&number) $(n=33)$} & \multirow{2}{*}{$\begin{array}{l}\text { Positive results for } \\
\text { Helicobacter spp. } \\
\text { (percent\&number) } \\
(\mathrm{n}=27)\end{array}$} & \multirow{2}{*}{$\begin{array}{l}\text { Negative results } \\
\text { (percent \& number) } \\
(\mathrm{n}=9)\end{array}$} & \multirow[t]{2}{*}{$\mathrm{p}$} \\
\hline & $H h$ & $H f$ & $H b$ & Hs & $H f+H b$ & $H h+H s$ & $H h+H f$ & $H b+H s$ & $H f+H b+H s$ & & & \\
\hline \multicolumn{13}{|l|}{ Histopathology grading } \\
\hline \multicolumn{13}{|l|}{ (Day et al., 2008) } \\
\hline Normal & $3.0(1 / 33)$ & 0 & 0 & $3.0(1 / 33)$ & 0 & 0 & 0 & 0 & 0 & $7.4(2 / 27)$ & $11.1(1 / 9)$ & NS \\
\hline Mild gastritis & $15.2(5 / 33)$ & $3.0(1 / 33)$ & $3.0(1 / 33)$ & $6.1(2 / 33)$ & 0 & $18.2(6 / 33)$ & $3.0(1 / 33)$ & $3.0(1 / 33)$ & $6.1(2 / 33)$ & $44.4(12 / 27)$ & $33.3(3 / 9)$ & \\
\hline Moderate gastritis & $12.1(4 / 33)$ & $3.0(1 / 33)$ & $3.0(1 / 33)$ & 0 & $3.0(1 / 33)$ & $9.1(3 / 33)$ & 0 & 0 & 0 & $48.1(13 / 27)$ & $44.4(4 / 9)$ & \\
\hline Marked gastritis & 0 & 0 & 0 & 0 & 0 & $6.1(2 / 33)$ & 0 & 0 & 0 & 0 & $11.1(1 / 9)$ & \\
\hline \multicolumn{13}{|l|}{ Epithelial injury } \\
\hline Mild & $27.3(9 / 33)$ & $3.0(1 / 33)$ & 0 & $9.1(3 / 33)$ & $3.0(1 / 33)$ & $30.3(10 / 33)$ & 0 & $3.01 / 3(3)$ & $6.1(2 / 33)$ & $77.8(21 / 27)$ & $33.3(3 / 9)$ & 0.003 \\
\hline Moderate & $3.0(1 / 33)$ & $3.0(1 / 33)$ & $6.1(2 / 33)$ & 0 & 0 & 0 & $3.0(1 / 33)$ & 0 & 0 & $14.8(4 / 27)$ & $11.1(1 / 9)$ & \\
\hline \multicolumn{13}{|l|}{ Fibrosis/mucosal atrophy } \\
\hline Mild & $18.2(6 / 33)$ & $6.1(2 / 33)$ & $6.1(2 / 33)$ & $6.1(2 / 33)$ & 0 & $18.2(6 / 33)$ & 0 & 0 & $3.0(1 / 33)$ & $55.6(15 / 27)$ & $33.3(3 / 9)$ & NS \\
\hline Moderate & $3.0(1 / 33)$ & 0 & 0 & 0 & $3.0(1 / 33)$ & 0 & 0 & 0 & 0 & $3.7(1 / 27)$ & $11.1(1 / 9)$ & \\
\hline \multicolumn{13}{|l|}{ Intraepithelial lymphocytes } \\
\hline Mild & $15.2(5 / 33)$ & $3.0(1 / 33)$ & $6.1(2 / 33)$ & $6.1(2 / 33)$ & 0 & $15.2(5 / 33)$ & 0 & 0 & $6.1(2 / 33)$ & $29.6(8 / 27)$ & $11.1(1 / 9)$ & 0.016 \\
\hline Moderate & $3.0(1 / 33)$ & $3.0(1 / 33)$ & 0 & 0 & $3.0(1 / 33)$ & $9.1(3 / 33)$ & 0 & 0 & 0 & $14.8(4 / 27)$ & 0 & \\
\hline \multicolumn{13}{|c|}{ Lymphofollicular hyperplasia } \\
\hline Mild & $6.1(2 / 33)$ & 0 & 0 & 0 & $3.0(1 / 33)$ & 0 & 0 & 0 & 0 & $29.6(8 / 27)$ & $11.1(1 / 9)$ & NS \\
\hline $\begin{array}{l}\text { Bacterial density } \\
\text { (based on the IHC results) }\end{array}$ & & & & & & & & & & & NA & \\
\hline+ & 0 & 0 & 0 & 0 & 0 & 0 & 0 & 0 & 0 & $14.8(4 / 27)$ & & \\
\hline++ & $3.0(1 / 33)$ & 0 & 0 & 0 & $3.0(1 / 33)$ & 0 & 0 & 0 & 0 & $25.9(7 / 27)$ & & \\
\hline+++ & $24.2(8 / 33)$ & $6.1(2 / 33)$ & $6.1(2 / 33)$ & $9.1(3 / 33)$ & 0 & $33.3(11 / 33)$ & $3.0(1 / 33)$ & $3.0(1 / 33)$ & $6.1(2 / 33)$ & $51.9(14 / 27)$ & & \\
\hline
\end{tabular}
significant $(p>0.05)$ 


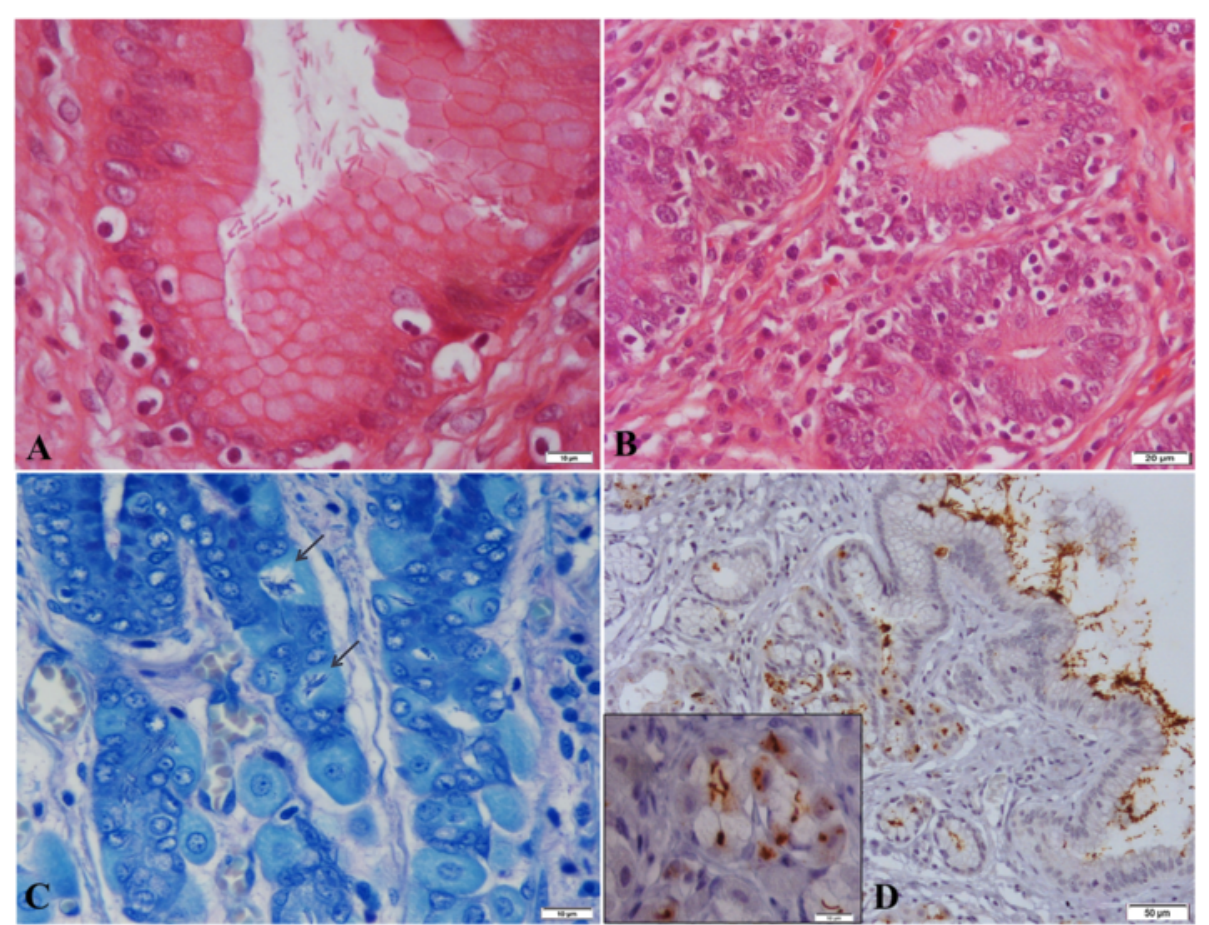

Figure 1 Helicobacter spp. in canine stomach. A) Numerous spiral-shaped bacteria colonizing the surface epithelium of the gastric pit. HE. Bar $=10 \mu \mathrm{m}$; B) Note the intraepithelial lymphocyte infiltration within the deeper gastric glands in the antral mucosa of a NHPH-positive dog. $\mathrm{HE}$. Bar $=20 \mu \mathrm{m}$. C) Presence of NHPH inside the parietal cells of the canine gastric body region (black arrow). MG. Bar $=10 \mu$ m; D) Large amounts of Helicobacter antigen within the superficial gastric mucus and in the lumen of gastric glands in the body region of canine stomach. Immunoperoxidase-diaminobenzidine stain with Mayer's haematoxylin counterstain. Bar $=50 \mu \mathrm{m}$. Inset shows Helicobacter antigen within parietal cells, sometimes detectable as well preserved spiral-shaped organisms or brown round dots. Immunoperoxidase-diaminobenzidine stain with Mayer's haematoxylin counterstain. Bar $=10 \mu \mathrm{m}$.

body samples (41/66) and in $70.6 \%$ of antral samples (36/51). Utilizing the MG stain, this was $68.2 \%$ for the body samples $(45 / 66)$ and $78.4 \%$ for the antral samples $(40 / 51)$. Helicobacter antigen was detected by immunochemistry in $84.9 \%(56 / 66)$ of the body samples and in $80.4 \%(41 / 51)$ of the antral samples (Table 3).

Further identification at species level was performed using Helicobacter species-specific qPCRs. Helicobacter spp. were detected in $47.8 \%$ of the animals (33/69) (Table 3). The majority of the samples were positive in the $H$. heilmannii specific qPCR. However, the amplicons

Table 3 Detection of Helicobacter spp. in the different stomach compartments of the canine stomach recurring to different diagnostic methods

\begin{tabular}{lllll}
\hline Gastric region & \multicolumn{4}{l}{ Detection methods } \\
\cline { 2 - 5 } & \multicolumn{4}{l}{ Positive (percent \& number) } \\
\cline { 2 - 5 } & HE & MG & IHC* & PCR \\
\hline Body $(n=66)$ & $62.1(41 / 66)$ & $68.2(45 / 66)$ & $84.8(56 / 66)$ & $37.9(25 / 66)$ \\
Antrum $(n=51)$ & $70.6(36 / 51)$ & $78.4(40 / 51)$ & $80.4(41 / 51)$ & $51.0(41 / 51)$
\end{tabular}

Legend: HE: haematoxylin-eosin; MG: modified Giemsa stain; IHC: immunohistochemistry; PCR: polymerase chain reaction.

*The positive results obtained with IHC did not differ significantly across each stomach region $(p>0.05)$. showed only approximately $92 \%$ homology with $H$. heilmanni s.s. Therefore, these cases were reclassified as $H$. heilmannii-like.

In $51.5 \%(17 / 33)$ of the positive samples, only one Helicobacter species was identified while mixed infections were detected in $48.5 \%(16 / 33)$ (Table 2). H. heilmanniilike organisms were the most commonly found (22/33 or $66.7 \%)$, being identified in ten dogs as a single infection and in 12 dogs as mixed infections. H. salomonis was the second most prevalent species (17/33 or 51.5\%) although it was mainly found in association with other $\mathrm{NHPH}$ (42\%) rather than alone (9.1\%). Equal proportions of $H$. felis and H. bizzozeronnii were detected (6/33 or 18.2\%), either as single (6.3\%) or mixed infections (12.1\%). Mixed infections with $H$. heilmannii-like and $H$. salomonis were most frequently encountered (33.3\%) (Table 2). In the body area, the most frequently identified species was $H$. salomonis $(44.0 \%)$ whereas in the antrum the most prevalent species was $H$. heilmannii-like (57.7\%) (Table 4).

There was a significant correlation between the presence of Helicobacter spp. and both mild to moderate epithelial injury and mild to moderate intraepithelial lymphocyte infiltration (Figure 1B) of the canine stomach ( $<<0.05)$. No statistically significantly correlations were found between 


\begin{tabular}{|c|c|c|}
\hline \multirow{2}{*}{$\begin{array}{l}\text { Specific PCR-Helicobacter spp. } \\
\text { positive results }\end{array}$} & \multicolumn{2}{|c|}{ Gastric region (percent \& number) } \\
\hline & $\begin{array}{l}\text { Body } \\
(n=25)\end{array}$ & $\begin{array}{l}\text { Antrum } \\
(n=26)\end{array}$ \\
\hline H. heilmannii-like & $24.0(6 / 25)$ & $57.7(15 / 26)$ \\
\hline H. salomonis & $44.0(11 / 25)$ & $7.7(2 / 26)$ \\
\hline H. felis & $8.0(2 / 25)$ & $3.8(1 / 26)$ \\
\hline H. bizzozeronnii & $4.0(1 / 25)$ & $11.5(3 / 26)$ \\
\hline H. felis + H. bizzozeronnii & $4.0(1 / 25)$ & $3.8(1 / 26)$ \\
\hline H. heilmannii-like + H. salomonis & $8.0(2 / 25)$ & $11.5(3 / 26)$ \\
\hline H. heilmannii-like + H. felis & $4.0(1 / 25)$ & $3.8(1 / 26)$ \\
\hline H. felis $+H$. salomonis & $4.0(1 / 25)$ & 0 \\
\hline
\end{tabular}

Helicobacter infection and gastric mucosal atrophy or fibrosis, lamina propria lymphoplasmacytic infiltration or lymphofollicular hyperplasia. No significant differences were detected regarding the bacterial colonisation density between both stomach regions ( $\mathrm{p}>0.05)$.

The number of Helicobacter-positive cases detected with the different methods differed significantly $(\mathrm{p}<0.05)$. Positive IHC results did not differ significantly across each stomach region $(\mathrm{p}>0.05)$, while the numbers obtained with HE, GM and qPCR differed significantly between the body and the antrum $(\mathrm{p}<0.05)$.

\section{Discussion}

In this study, a high prevalence of gastritis was observed (95.7\%). These results are in agreement with other studies reporting the occurrence of gastritis as a common finding in dogs $[14,31,32]$. In contrast, gastric erosions or ulcers were rarely found in these animals.

$\mathrm{NHPH}$ infection was determined by four methods (HE, MG, IHC and qPCR) and a prevalence of $87.0 \%$ in dogs was detected. These results are consistent with those available in the literature, which documented high prevalence of NHPH in the canine gastric mucosa [12,19,33-35]. In our study canine NHPH infection was significantly accompanied by mild to moderate intraepithelial lymphocyte infiltration and mild to moderate gastric epithelial injury, regardless of the stomach location. A clear relationship between canine gastritis and Helicobacter infection was, however, not established which is in accordance with results of others $[11,14,15,34]$.

In a previous investigation, the percentage of Helicobacter-positive cases detected after HE staining of canine gastric samples was $17.5 \%$ [24]. In the current study, all the samples were examined by two pathologists highly experienced in the detection of Helicobacter spp. organisms after routine staining. This may have played a role in the higher detection rate $(65.2 \%)$ reported here.
In agreement with previous studies, $\mathrm{NHPH}$ were often observed not only in the superficial mucus and within the gastric glands but also intracellularly, in the cytoplasm of parietal cells $[31,33,36]$ (Figure $1 C$ and D). Spiral-shaped organisms present in this particular subcellular location were difficult to detect after HE and MG staining due to the cytoplasm granulation of the parietal cells. In our hands, IHC appeared to be a very valuable technique to identify NHPH within these cells (Figure 1D). Overall, IHC staining showed the highest Helicobacter-positive values (82.6\%). This finding is in agreement with other results showing that commercially available antibodies against $H$. pylori are useful for the detection of Helicobacter spp. in paraffin embedded samples from dog stomachs [24,26,36].

Previous studies reported no statistically significant difference between the detection of Helicobacter organisms by IHC and PCR techniques ( $>$ > 0.05) [24]. Chung et al. (2014) reported that the PCR assay had higher sensitivity and specificity than the other methods [4]. However, in our study, the prevalence rate of Helicobacter spp. obtained with the qPCR was the lowest (47.8\%). Previous investigations have shown that formalin fixation and paraffin embedding hamper PCR analysis [37,38]. Sjödin et al. (2011) compared the efficiency of the DNA amplification from fresh $(n=28)$ and paraffin embedded $(n=28)$ samples for identification of Helicobacter spp. from different organs (feline stomach, duodenum, liver and pancreas) and concluded that the mean value of DNA concentration achieved was higher when obtained from fresh tissues [39]. DNA analysis of paraffin embedded tissue samples using PCR/qPCR may be compromised due to DNA fragmentation, inhibiting substances, or a combination of both. The formalin fixation may indeed cause DNA fragmentation as well as partial destruction of DNA $[38,40]$ and the PCR reactions may also be inhibited by formalin residue [37]. The negative effects of formalin are directly related to the duration of the fixation [40]. Although the samples included in this study were all processed in the same laboratory and therefore subjected to the same standard protocols, duration of fixation may vary between samples due to variation in time interval between sample collection and their arrival at the laboratory.

Different molecular approaches for the identification of $\mathrm{NHPH}$ species have been addressed [4,14,24,28]. Techniques based on detection or sequencing of $16 \mathrm{~S}$ or $23 \mathrm{~S}$ rRNA-encoding genes can, however, not distinguish between the different canine and feline gastric Helicobacter species, whereas tests based on detection or sequencing of the $h s p 60$ gene, the urease A and B genes or $\operatorname{gyrB}$ gene allow identification of these bacteria to the species level [9].

In our study, amplicons obtained in the $H$. heilmannii specific qPCR only showed approximately 92\% homology with $H$. heilmannii, which so far has only been cultured from the gastric mucosa of cats. Therefore, these cases 
were reclassified as $H$. heilmannii-like. At this moment it is not clear whether $H$. heilmannii-like might represent a new species or a host-adapted variant of $H$. heilmannii.

As previously reported, mixed infections are a common and interesting finding in dogs and cats. Mixed colonisation of the same niche by two or more Helicobacter species often occurs and may provide conditions for recombination and genetic exchange between these species. Further studies are necessary to determine if this might play a role in sequence differences in the ure $A B$ gene cluster between $H$. heilmannii and $H$. heilmannii-like. An appropriate approach might be in vitro isolation and whole genome sequencing of $H$. heilmannii-like from dogs.

According to our results, $H$. heilmannii-like organisms were the most commonly found and $H$. salomonis was mainly found in association with other than NHPH rather than alone. Equal proportions of $H$. felis and $H$. bizzozeronnii were detected, either as single or mixed infections, respectively. Some authors describe $H$. felis as the most commonly found species in dogs [15]. In contrast, in dogs from Finland, Switzerland, the United States and Denmark H. bizzozeronii and H. salomonis were the most common, followed by $H$. felis and $H$. heilmannii $[27,28,33]$. In dogs from Belgium, Van den Bulck et al. [19] also documented that $H$. bizzozeronii was the most prevalent Helicobacter species, as it was identified in $20.0 \%$ of the dogs as a single infection and in $50.0 \%$ of the dogs as mixed infections. Single infections with $H$. felis or $H$. heilmannii-like were sporadically encountered, while single infections with $H$. salomonis were not identified in any sample [19].

In our study, the prevalence of $\mathrm{NHPH}$ was different in both canine stomach regions. Recently, the in vitro binding capacity of gastric Helicobacter species to canine gastric mucosa was assessed and it was concluded that $H$. heilmannii was the species that adhered the most, followed by $H$. felis, $H$. bizzozeronnii and $H$. salomonis. This tendency was observed in both stomach compartments [41]. Despite its low binding capacity in vitro, $H$. salomonis appears to be more effective in colonizing the body stomach of the dog. Regarding the antrum region, the in vitro binding assays are in accordance with the results herein obtained and support the high prevalence of $H$. heilmannii-like organisms in this specific location [41].

Given these results and the high proportion of dogs showing the $H$. heilmannii-like and $H$. salomonis bacterial combination, it seems plausible that direct interaction between at least these two species may occur. This high percentage of mixed infections comprising $H$. salomonis may suggest that the colonization capacity of this species in the canine gastric mucosa may be enhanced when associated with other NHPH. However, further studies are needed in order to clarify this hypothesis.

\section{Conclusions}

Taken together, all these results suggest that, despite the high incidence and worldwide distribution of $\mathrm{NHPH}$, the presence of specific Helicobacter species may vary between geographic regions. NHPH infections were significantly accompanied by mild to moderate intraepithelial lymphocyte infiltration and mild to moderate gastric epithelial injury, but a clear relationship between gastritis and Helicobacter infection could not be established.

\section{Competing interests}

None of the authors of this paper has a financial or personal relationship with other people or organisations that could inappropriately influence or bias the content of the paper.

\section{Authors' contributions}

IA, MAT and FG participated in the design of the study. IA wrote the manuscript. IA, ST and ALS collected the samples. ST and ALS carried out the $\mathrm{HE}$ and $\mathrm{IHC}$ staining. AS carried out the molecular studies. OA performed the statistical analysis. IA, MAT, FG reviewed HE and IHC slides. AS, FH, CAR and FG drafted the manuscript and revised it critically for important intellectual content. All authors read and approved the final manuscript.

\section{Acknowledgments}

I. Amorim (SFRH/BD/76237/2011) acknowledges the Portuguese Foundation for Science and Technology (FCT) for financial support. IPATIMUP integrates the i3S Research Unit, which is partially supported by FCT. This work is funded by FEDER funds through the Operational Programme for Competitiveness Factors-COMPETE and National Funds through the FCT-Foundation for Science and Technology, under the projects "PEst-C/SAU/LA0003/2013" and PTDC/CVT/117610/2010.

\section{Author details}

${ }^{1}$ Instituto de Investigação e Inovação em Saúde, Universidade do Porto, Porto, Portugal. ${ }^{2}$ IPATIMUP - Institute of Molecular Pathology and Immunology of the University of Porto, Rua Dr. Roberto Frias s/n, 4200-465 Porto, Portugal. ${ }^{3}$ Institute of Biomedical Sciences Abel Salazar (ICBAS), University of Porto, Rua Jorge Viterbo Ferreira nr.228, 4050-313 Porto, Portugal. ${ }^{4}$ Faculty of Veterinary Medicine, Ghent University, Salisburylaan 133, Merelbeke B-9820, Belgium. ${ }^{5}$ CECAV, Centro de Ciência Animal e Veterinária, Universidade de Trás-os-Montes e Alto Douro, Quinta de Prados, 5000-801 Vila Real, Portugal. ${ }^{6}$ Faculty of Veterinary Medicine, University of Agricultural Sciences and Veterinary Medicine, Cluj-Napoca, Romania. ${ }^{7}$ Faculty of Medicine, University of Porto, Alameda Prof. Hernâni Monteiro, 4200-319 Porto, Portugal.

Received: 19 December 2014 Accepted: 19 March 2015 Published online: 16 April 2015

\section{References}

1. Baele M, Decostere A, Vandamme P, Ceelen L, Hellemans A, Mast J, et al. Isolation and characterization of Helicobacter suis sp. nov. from pig stomachs. Int J Syst Evol Microbiol. 2008;58(Pt 6):1350-8.

2. Buczolits S, Hirt R, Rosengarten R, Busse HJ. PCR-based genetic evidence for occurrence of Helicobacter pylori and novel Helicobacter species in the canine gastric mucosa. Vet Microbiol. 2003;95(4):259-70.

3. Ekman E, Fredriksson M, Trowald-Wigh G. Helicobacter spp. in the saliva, stomach, duodenum and faeces of colony dogs. Vet J. 2013;195(1):127-9.

4. Chung TH, Kim HD, Lee YS, Hwang CY. Determination of the prevalence of Helicobacter heilmannii-like organisms type 2 (HHLO-2) infection in humans and dogs using non-invasive genus/species-specific PCR in Korea. J Vet Med Sci. 2014;76(1):73-9.

5. Haesebrouck F, Pasmans F, Flahou B, Smet A, Vandamme P, Ducatelle R. Non-Helicobacter pylori Helicobacter species in the human gastric mucosa: a proposal to introduce the terms $\mathrm{H}$. heilmannii sensu lato and sensu stricto. Helicobacter. 2011;16(4):339-40.

6. Lavelle JP, Landas S, Mitros FA, Conklin JL. Acute gastritis associated with spiral organisms from cats. Dig Dis Sci. 1994;39(4):744-50. 
7. Morgner A, Lehn N, Andersen LP, Thiede C, Bennedsen M, Trebesius K, et al. Helicobacter heilmannii-associated primary gastric low-grade MALT lymphoma: complete remission after curing the infection. Gastroenterology. 2000;118(5):821-8.

8. De Bock M, Van den Bulck K, Hellemans A, Daminet S, Coche JC, Debongnie JC, et al. Peptic ulcer disease associated with Helicobacter felis in a dog owner. Eur J Gastroenterol Hepatol. 2007;19(1):79-82.

9. Haesebrouck F, Pasmans F, Flahou B, Chiers K, Baele M, Meyns T, et al. Gastric helicobacters in domestic animals and nonhuman primates and their significance for human health. Clin Microbiol Rev. 2009;22(2):202-23.

10. Geyer C, Colbatzky F, Lechner J, Hermanns W. Occurrence of spiral-shaped bacteria in gastric biopsies of dogs and cats. Vet Rec. 1993;133(1):18-9.

11. Hermanns W, Kregel K, Breuer W, Lechner J. Helicobacter-like organisms: Histopathological examination of gastric biopsies from dogs and cats. J Comp Pathol. 1995;112(3):307-18.

12. Hwang CY, Han HR, Youn HY. Prevalence and clinical characterization of gastric Helicobacter species infection of dogs and cats in Korea. J Vet Sci. 2002;3(2):123-33.

13. Lecoindre PCM, Peyrol S, Boude M, De Montclos H. Contribution a l'etude des helicobacteries de l'estomac du chien et de leur role pathogene. Revue Medicine Veterinaire. 1995;146(671):80.

14. Polanco R, Salazar V, Reyes N, García-Amado MA, Michelangeli F. High prevalence of dna from non-H. pylori helicobacters in the gastric mucosa of venezuelan pet dogs and its histological alterations. Rev Inst Med Trop Sao Paulo. 2011;53:207-12.

15. Eaton KA, Dewhirst FE, Paster BJ, Tzellas N, Coleman BE, Paola J, et al. Prevalence and varieties of Helicobacter species in dogs from random sources and pet dogs: animal and public health implications. J Clin Microbiol. 1996;34(12):3165-70.

16. Henry GA, Long PH, Burns JL, Charbonneau DL. Gastric spirillosis in beagles. Am J Vet Res. 1987;48(5):831-6.

17. Simpson KW, McDonough PL, Strauss-Ayali D, Chang YF, Harpending P, Valentine BA. Helicobacter felis infection in dogs: effect on gastric structure and function. Vet Pathol. 1999;36(3):237-48.

18. Baele M, Pasmans F, Flahou B, Chiers K, Ducatelle R, Haesebrouck F. Non-Helicobacter pylori helicobacters detected in the stomach of humans comprise several naturally occurring Helicobacter species in animals. FEMS Immunol Med Microbiol. 2009:55(3):306-13.

19. van den Bulck K, Decostere A, Baele M, Baele M, Driessen A, Debongnie J, et al. Identification of non-Helicobacter pylori spiral organisms in gastric samples from humans, dogs, and cats. J Clin Microbiol. 2005;43:2256-60.

20. Van den Bulck K, Decostere A, Baele M, Vandamme P, Mast J, Ducatelle R, et al. Helicobacter cynogastricus sp. nov., isolated from the canine gastric mucosa. Int J Syst Evol Microbiol. 2006;56(Pt 7):1559-64

21. Yamasaki K, Suematsu H, Takahashi T. Comparison of gastric lesions in dogs and cats with and without gastric spiral organisms. J Am Vet Med Assoc. 1998:212(4):529-33.

22. Anacleto TP, Lopes LR, Andreollo NA, Bernis Filho WO, Resck MC, Macedo A. Studies of distribution and recurrence of Helicobacter spp. gastric mucosa of dogs after triple therapy. Acta cirurgica brasileira / Sociedade Brasileira para Desenvolvimento Pesquisa em Cirurgia. 2011;26(2):82-7.

23. Cattoli G, van Vugt R, Zanoni RG, Sanguinetti V, Chiocchetti R, Gualtieri M, et al. Occurrence and characterization of gastric Helicobacter spp. in naturally infected dogs. Vet Microbiol. 1999;70(3-4):239-50.

24. Prachasilpchai W, Nuanualsuwan $\mathrm{S}$, Chatsuwan $\mathrm{T}$, Techangamsuwan $\mathrm{S}$, Wangnaitham S, Sailasuta A. Diagnosis of Helicobacter spp. infection in canine stomach. J Vet Sci. 2007;8(2):139-45.

25. Recordati C, Gualdi V, Craven M, Sala L, Luini M, Lanzoni A, et al. Spatial distribution of Helicobacter spp. in the gastrointestinal tract of dogs. Helicobacter. 2009;14(3):180-91.

26. Gombač M, Švara T, Černe M, Pogačnik M. Histological changes in stomachs of apparently healthy dogs infected with helicobacter. Acta Vet Brno. 2010;60(2-3):173-82.

27. Jalava K, On SL, Vandamme PA, Happonen I, Sukura A, Hanninen ML. Isolation and identification of Helicobacter spp. from canine and feline gastric mucosa. Appl Environ Microbiol. 1998;64(10):3998-4006.

28. Priestnall SL, Wiinberg B, Spohr A, Neuhaus B, Kuffer M, Wiedmann M, et al. Evaluation of "Helicobacter heilmannii" subtypes in the gastric mucosas of cats and dogs. J Clin Microbiol. 2004;42(5):2144-51.

29. Day MJ, Bilzer T, Mansell J, Wilcock B, Hall EJ, Jergens A, et al. Histopathological standards for the diagnosis of gastrointestinal inflammation in endoscopic biopsy samples from the dog and cat: a report from the World Small Animal Veterinary Association Gastrointestinal Standardization Group. J Comp Pathol. 2008;138 Suppl 1:S1-43.

30. O'Rourke J, Solnick J, Neilan B, Seidel K, Hayter R, Hansen L, et al. Description of "Candidatus Helicobacter heilmannii" based on DNA sequence analysis of $16 \mathrm{~S}$ rRNA and urease genes. Int J Syst Evol Microbiol. 2004;54:2203-11.

31. Happonen I, Saari S, Castren L, Tyni O, Hanninen ML, Westermarck E. Comparison of diagnostic methods for detecting gastric Helicobacter-like organisms in dogs and cats. J Comp Pathol. 1996;115(2):117-27.

32. Neiger R, Simpson KW. Helicobacter infection in dogs and cats: facts and fiction. J Vet Intern Medicine. 2000;14(2):125-33.

33. Wiinberg B, Spohr A, Dietz HH, Egelund T, Greiter-Wilke A, McDonough SP, et al. Quantitative Analysis of Inflammatory and Immune Responses in Dogs with Gastritis and Their Relationship to Helicobacter spp. Infection. J Vet Intern Med. 2005;19(1):4-14.

34. Shabestari AS, Mohammadi M, Jamshidi S, Sasani F, Bahadori A, Oghalaie A. Assessment of chronic gastritis in pet dogs and its relation with helicobacter-like organisms. Pakistan J Biol Sci. 2008;11(11):1443-8.

35. Moutinho F, Thomassian A, Watanabe M, Suzano S, Sequeira J. Prevalence of helicobacters and alterations in gastric mucosa of healthy dogs. Arquivo Brasileiro de Medicina Veterinária e Zootecnia. 2007;59(4):1080-3.

36. Scanziani E, Simpson KW, Monestiroli S, Soldati S, Strauss-Ayali D, Del Piero F. Histological and immunohistochemical detection of different Helicobacter species in the gastric mucosa of cats. J Vet Diagn. 2001;13(1):3-12.

37. Farrugia A, Keyser C, Ludes B. Efficiency evaluation of a DNA extraction and purification protocol on archival formalin-fixed and paraffin-embedded tissue. Forensic Sci Int. 2010;194(1-3):e25-8.

38. Gilbert MT, Haselkorn T, Bunce M, Sanchez JJ, Lucas SB, Jewell LD, et al. The isolation of nucleic acids from fixed, paraffin-embedded tissues-which methods are useful when? PLoS One. 2007;2(6), e537.

39. Sjodin S, Trowald-Wigh G, Fredriksson M. Identification of Helicobacter DNA in feline pancreas, liver, stomach, and duodenum: comparison between findings in fresh and formalin-fixed paraffin-embedded tissue samples. Res Vet Sci. 2011:91(3):e28-30.

40. Miething F, Hering S, Hanschke B, Dressler J. Effect of fixation to the degradation of nuclear and mitochondrial DNA in different tissues. Histochem Cytochem. 2006;54(3):371-4.

41. Amorim I, Freitas DP, Magalhães A, Faria F, Lopes C, Faustino AM, et al. A comparison of Helicobacter pylori and non-Helicobacter pylori Helicobacter spp. Binding to Canine Gastric Mucosa with Defined Gastric Glycophenotype. Helicobacter. 2014;19(4):249-59.

\section{Submit your next manuscript to BioMed Central and take full advantage of:}

- Convenient online submission

- Thorough peer review

- No space constraints or color figure charges

- Immediate publication on acceptance

- Inclusion in PubMed, CAS, Scopus and Google Scholar

- Research which is freely available for redistribution

Submit your manuscript at www.biomedcentral.com/submit
C Biomed Central 